\title{
Peningkatan Kualitas dan Kuantitas Biji Kakao Melalui Intensifikasi Perawatan Kakao, Introduksi Alat Budidaya, dan Pengering Sistem Hybrid
}

\section{Improving the Quality and Quantity of Cocoa Beans through Intensification of Cacao Maintenance, Introduction of Cultivation Equipment, and Hybrid System Dryer}

\author{
Mercy Bientri Yunindanova ${ }^{1 *}$, Dimas Rahadian Aji Muhammad ${ }^{2}$, Sigit Prabawa $^{2}$ \\ ${ }^{1}$ Program Studi Agroteknologi, Fakultas Pertanian, Universitas Sebelas Maret (UNS), Jl. Ir. Sutami 36A, Kentingan, \\ Surakarta, Jawa Tengah, Indonesia \\ ${ }^{2}$ Program Studi Ilmu Teknologi Pangan, Fakultas Pertanian, Universitas Sebelas Maret (UNS), Jl. Ir. Sutami 36A, \\ Kentingan, Surakarta, Jawa Tengah, Indonesia
}

\begin{tabular}{l}
\hline Info Artikel \\
\hline Diterima 11 Oktober 2020 \\
Ditelaah 30 Nopember 2020 \\
Disetujui 01 Juni 2021 \\
Tersedia daring 30 Juni 2021 \\
*Penulis untuk korespondensi \\
mercybientri_fp@ staff.uns.ac.id \\
\hline \\
Kata Kunci: \\
Kakao, \\
Perawatan kakao, \\
Pengering sistem hybrid
\end{tabular}

Keywords:

Cacao,

Cacao plantation maintenance, Hybrid system

\section{ABSTRAK}

Desa Putat, Kecamatan Patuk, Kabupaten Gunung Kidul merupakan salah satu sentra produksi kakao di Yogjakarta. Produk biji kakao di daerah tersebut telah dipasarkan meluas di berbagai daerah Indonesia. Dalam menunjang kontinuitas produksi biji kakao, selama ini petani menghadapi kendala dalam perawatan serta pengeringan kakao. Untuk itu, kegiatan pengabdian masyarakat ini bertujuan untuk peningkatan kualitas dan kuantitas biji kakao melalui intensifikasi perawatan dan introduksi alat pengering biji kakao sistem hybrid. Mitra yang terlibat dalam kegiatan ini adalah Kelompok Tani Kakao Sido Dadi dan Industri pengolahan kakao dan cokelat "Joglo Coklat" di Patuk, Gunung Kidul, Yogjakarta. Kegiatan dilakukan dalam beberapa tahap yaitu 1) pengumpulan data dasar, 2) sosialisasi perawatan tanaman kakao, 3) sosialisasi pengeringan biji kakao, 4) introduksi alat perwatan tanaman kakao, 5) pembangunan kumbung pengering sistem hybrid, 6) serah terima alat, dan 7) evaluasi respon masyarakat. Hasil kegiatan menunjukkan bahwa pemberian informasi dan introduksi alat untuk kegiatan perawatan tanaman kakao berdampak positif terhadap mitra. Dari kuisioner yang dibagikan, mitra menyatakan kebermanfaatan kegiatan ini dan keinginan untuk kegiatan berkelanjutan. Introduksi alat perawatan dan kumbung pengering memudahkan petani dalam melaksanakan kegiatan budidaya, panen dan pasca panen biji kakao sehingga dapat meningkatkan kualitas dan kuantitas biji kakao yang dihasilkan.

\section{ABSTRACT}

Putat village, Patuk district, Gunung Kidul regency is one of cocoa production center in Yogjakarta. Cocoa bean products in this region have been marketed not only in Yogjakarta but also several areas in Indonesia. In order to support production continuity of cocoa bean productions, to date the farmers face obtacles in cacao plantation maintenance and cocoa beans drying. Thus, this activity aimed to increase quality and quantity of cocoa beans through maintenance intensifications of cacao and introduction of cacao cultivation equipments and cocoa beans drying hybrid system. Partner in this activities were Kelompok Tani Kakao Sido Dadi and cocoa dan chocolate production industry “Joglo Coklat" located in Patuk, Gunung Kidul, Yogjakarta. The activities were conducted in several stages including 1) basic data collection, 2) socialization of cacao plantation maintenance, 3) socialization of cocoa beans drying, 4) introduction of cultivation equipments, 5) contruction of drying chamber, 6) handover of equipment, and 7) evaluation of parnter response. The results of the activity indicated that the provision of information and the introduction of equipment for cacao plant maintenance activities had a positive impact on partners. From the questionnaires, the partners stated the benefits of this activity and the desire for sustainable activities. The introduction of maintenance equipment and cocoa beans drying made it easier for farmers to carry out 
cultivation, harvest and post-harvest activities of cocoa beans so would be able to improve the quality and quantity of cocoa beans.

ISSN 2685-0354 (Media Online). Diterbitkan oleh Universitas Prof. Dr. Hazairin, SH. Ini merupakan jurnal bebas akses di bawah lisensi Creative Commons Atribution 4.0 International (https://creativecommons.org/licenses/by/4.0

\section{PENDAHULUAN}

Kakao merupakan salah satu komoditas unggulan perkebunan Indonesia. Komoditas ini memiliki peran yang sangat signifikan mengingat kontribusinya terhadap penyediaan lapangan kerja, peningkatan pendapat masyarakat, peningkatan devisa negara dan menjaga kelestarian sumber daya alam. Saat ini, Indonesia merupakan negara pengekspor biji kakao terbesar ke-5 di dunia, yang sebelumnya pernah menempati posisi ke-3. Peningkatan produktivitas biji kakao merupakan salah satu metode dalam meningkatkan daya saing kakao Indonesia di dunia (Kindangen 2017).

Rata-rata produktivitas biji kakao di Indonesia mencapai $742 \mathrm{~kg} \mathrm{ha}^{-1}$ pada tahun 2019 sedangkan potensi produksinya dapat melebihi 1,5 ton ha-1 (Direktorat Jenderal Perkebunan, 2019). Peningkatan produksi ini layak untuk menjadi fokus semua pihak mengingat permintaan biji kakao di dunia kian meningkat. Selain sisi kuantitas, sisi kualitas juga wajib menjadi perhatian seiring dengan tuntutan pasar dunia yang semakin memperhatikan mutu. Pengembangan tanaman kakao ke depan harus diprioritaskan pada usaha untuk menghasilkan produk biji kakao yang bermutu tinggi agar terjadi peningkatan pendapatan masyarakat (Manalu 2018).

Upaya peningkatan produktivitas tanaman kakao dapat dilakukan melalui optimalisasi perawatan kakao dan penanganan pasca panen yang tepat. Perawatan merupakan kegiatan pemeliharaan semua aspek pertumbuhan tanaman kakao mulai dari periode belum menghasilkan hingga periode tanaman menghasilkan. Selain itu, perawatan merupakan upaya memastikan tanaman tetap dapat berproduksi secara ekonomis. Aspek perawatan seringkali kurang diperhatikan mengingat tingkat pemahaman dan alat perawatan. Perawatan yang kurang optimal dapat menurunkan produktivitas tanaman (Asare and David, 2011).

Penangan pasca panen kakao menentukan tingkat mutu biji yang dihasilkan. Kegiatan penanganan pasca panen kakao meliputi fermentasi dan pengeringan. Kegiatan fermentasi merupakan tahapan krusial untuk menonaktifkan biji dan menghasilkan aroma coklat. Tahap pengeringan merupakan tahap lanjutan untuk memastikan kadar air yang berhubungan dengan tingkat kontaminasi biji kakao (Deus et al. 2018). Kegiatan pengeringan yang tepat berkorelasi dengan kualitas biji kakao (Lasisi, 2014).

Dalam upaya meningkatkan daya saing produk biji kakao Indonesia, kegiatan ini dilakukan bersama mitra petani kakao. Sehingga kegiatan ini bertujuan untuk peningkatan kualitas dan kuantitas biji kakao melalui intensifikasi perawatan dan introduksi alat pengering biji kakao sistem hybrid. Untuk itu, kegiatan pengabdian kepada masyarakat ini diharapkan dapat menjadi alternatif solusi atas masalah terkait kakao menuju produksi kakao Indonesa yang berkelanjutan.

\section{METODE}

Kegiatan pengabdian ini dilaksanakan di dusun Gumawang, Desa Putat, Kecamatan Patuk, Kabupaten Gunung Kidul, Daerah Istimewa Yogjakarta pada bulan Agustus hingga Oktober 2020. Peserta kegiatan berjumlah 30 orang yang terdiri atas anggota kelompok Tani Sido Dadi dan anggota Industri Pengolahan Kakao dan Cokelat "Joglo Coklat". Kegiatan pengabdian dilakukan dalam bentuk pemberdayaan. Pemberdayaan dilakukan melalui peningkatan pengetahuan dan ketrampilan yang berfokus pada potensi petani dan komoditas kakao. Kegiatan pemberdayaan merupakan suatu konsep pembanguan bidang ekonomi yang bersifat people-centered dan participatory (Noor, 2011).

Untuk menghadapi masalah yang dihadapi mitra, alternatif solusi yang ditawarkan berpedoman pada kebutuhan dan harapan mitra. Dalam kegiatan ini tim pengabdi berupaya memfasilitasi melalui integrasi ilmu pengetahuan dan teknologi (IPTEK) serta penerapan hasil penelitian di perguruan tinggi. Kegiatan dilakukan menjadi beberapa tahap yaitu 1) pengumpulan data dasar, 2) sosialisasi perawatan tanaman kakao, 3) sosialisasi pengeringan biji kakao, 4) introduksi alat perawatan tanaman kakao, 5) pembangunan kumbung pengering sistem hybrid, 6) serah terima alat, dan 7) evaluasi respon masyarakat.

Pengumpulan data dasar guna memastikan kesesuaian materi dan teknologi yang akan diintroduksi ke masyarakat, tim pengabdi melakukan kajian lapang melalui wawancara dan survai pada lahan kebun kakao milik kelompok Tani Sido Dadi. Interview juga dilakukan terhadap anggota Industri pengolahan kakao dan cokelat "Joglo Coklat”. Survai dilakukan untuk melihat langsung kondisi kebun kakao dan tanaman kakao. Sedangkan wawancara 
digunakan untuk mengenali mitra dari aspek sumber daya alam, tanaman, maupun sumber daya manusia. Selain itu, kegiatan kajian lapang awal juga penting dilakukan untuk mengkomunikasikan masalah dan solusi yang terjadi di lapang.

Tahap sosialisasi tentang perawatan tanaman kakao dan pengeringan biji kakao dilakukan dengan metode ceramah dan diskusi. Tahap introduksi alat dilakukan dengan pemberian bantuan alat-alat perawatan tanaman kakao dan alat-alat panen. Setelah introduksi alat, kegiatan dilanjutkan dengan praktek perawatan kakao. Hal ini dilakukan dengan praktik pemangkasan tanaman kakao. Pembangunan kumbung pengering diawali dengan pembuatan desain, persiapan alat dan bahan, penentuan lokasi dan proses pembangunan kumbung. Setalah kumbung siap digunakan, kegiatan diakhiri dengan serah terima dan evaluasi kegiatan. Evaluasi kegiatan dilakukan melalui pemberian kuisioner pada mitra tentang kebermanfaatan dan tindak lanjut.

\section{HASIL DAN PEMBAHASAN}

\section{Kondisi Umum Mitra dan Pasca Sosialisasi}

Kelompok Tani Sido Dadi merupakan kelompok tani yang berfokus pada kegiatan pembudidayaan tanaman kakao sejak 30 tahun yang lalu. Kelompok ini diketuai oleh bapak Edi dengan anggota sebanyak 61 orang. Selain tanaman origin yang ada di daerah Gunung Kidul, tanaman kakao yang telah dibudidayakan di daerah tersebut juga memperoleh bahan tanaman dalam agenda Gerakan Nasional Kakao (Gernas Kakao). Saat ini kebun Kelompok Tani Sido Dadi memiliki beberapa varietas diantaranya MCC 01, MCC 02, Criolo, Forastero, Lindak, ICCRI 03, ICCRI 04, ICCRI 07, Masamba dan KKM.

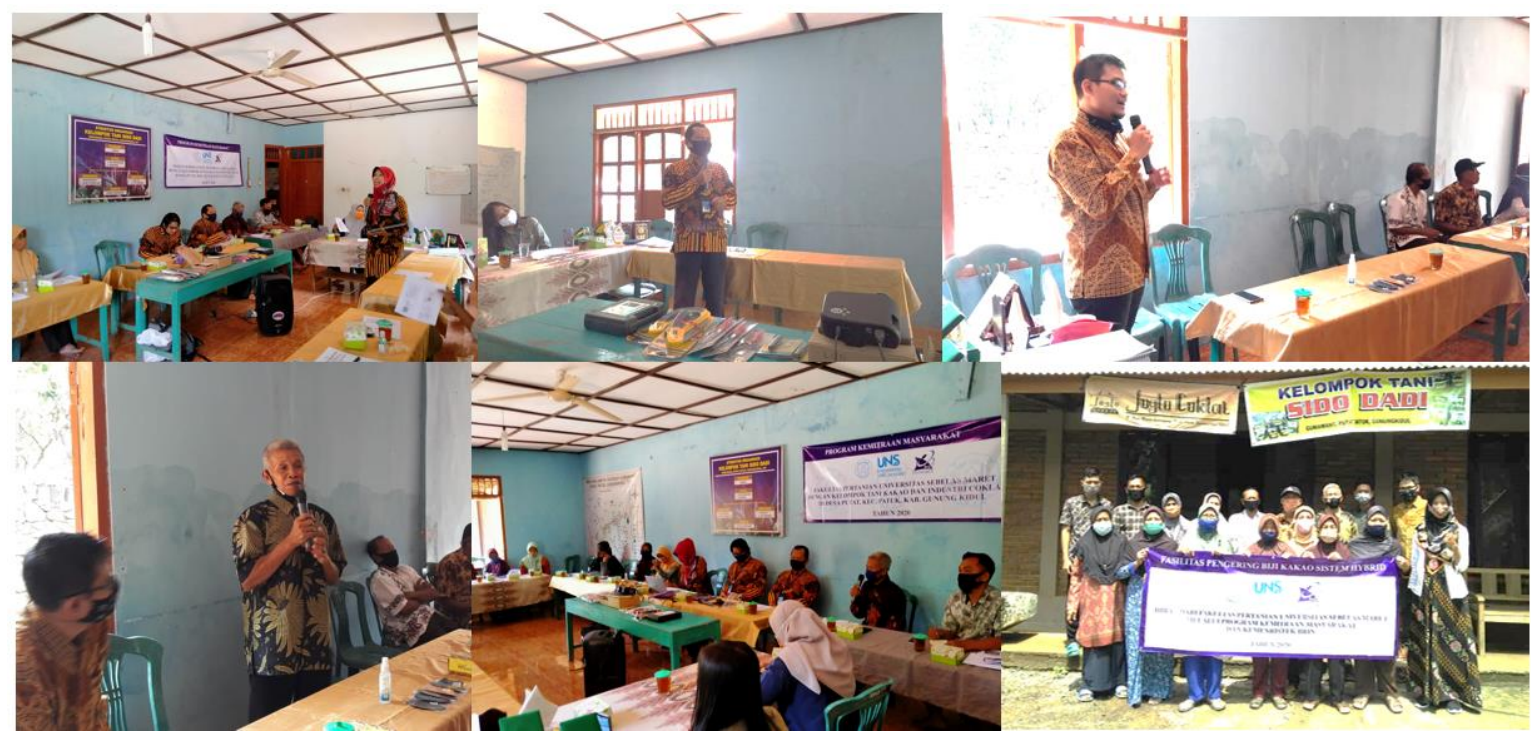

Gambar 1 Kegiatan Sosialisasi

Kelompok ini telah mengelola lahan kakao total 11 ha dengan lebih dari 10 ribu pohon kakao. Jumlah kapasitas panen mencapai $400 \mathrm{~kg}$ kakao kering setiap minggu. Kelompok Tani Sido Dadi sebagai penghasil biji kakao di Gunung Kidul sangat potensial mengingat lokasi ini berada pada sekitar Kawasan Wisata Utama di Gunung Kidul yang memiliki berbagai tempat wisata yang banyak dikunjungi wisatawan baik lokal maupun mancanegara. Tempat wisata tersebut di antaranya Bukit Bintang, Embung Nglangeran, Gunung Api Purba Nglangeran, dan Goa Pindul.

Biji kakao yang dihasilkan oleh Kelompok Tani Sido Dadi selain diolah pada industri pengolahan kakao dan cokelat "Joglo Coklat" serta beberapa usaha kecil dan menengah di Gunung Kidul, juga telah dipasarkan ke berapa daerah di antaranya Blitar, Bali, Makasar, Kalimantan, Aceh, dan Sumatra. Biji kakao dari kelompok ini telah secara rutin dikirim untuk diolah oleh industri pengolahan coklat diantaranya Coklat nDalem ${ }^{\mathrm{TM}}$, yang merupakan produsen olahan coklat di pusat kota Yogjakarta. Selain itu, beberapa produsen olahan coklat juga mengambil bahan dari Kelompok Tani Sido Dadi yaitu Coklat Monggo ${ }^{\mathrm{TM}}$ dan Coklat Moenier ${ }^{\mathrm{TM}}$. Biji coklat dari kelompok ini juga dikirimkan ke Singapura dan Perancis melalui pihak ke-3. Untuk memenuhi permintaan pasar, mulai tahun 2019, kebun kakao yang tergabung dalam kelompok Tani Sido Dadi juga menginisiasi kakao organik dengan mengandalkan kotoran sapi sebagai sumber pupuk organik utama. 
Potensi pasar biji kakao sangat besar dan perlu jaminan kontinuitas secara kualitas maupun kuantitas. Namun demikian, salah satu permasalahan yang dihadapi oleh Kelompok Tani Sido Dadi adalah terkait perawatan kakao. Pemeliharaan kebun kakao yang kurang optimal ditingkat petani disebabkan oleh faktor kurangnya tingkat pengetahuan petani, keterbatasan alat dan modal, sehingga menyebabkan produksi yang dihasilkan belum maksimal. Sehingga sosialisasi perawatan kakao dan introduksi alat perawatan dilakukan pada kegiatan ini (Gambar 1). Materi pada tahap ini menjelaskan tentang jenis perawatan tanaman kakao. Perawatan tanaman kakao terdiri atas 5 jenis yaitu 1) Penggantian tanaman yang tidak tumbuh optimal, 2) Pembersihan gulma, 3) Pemangkasan pohon kakao, 4) Pemberian pupuk, dan 5) Pemeliharaan dari hama dan penyakit. Dosis dan cara pemupukan berpengaruh terhadap produktivitas kakao (Faradilla, 2018). Pemangkasan sangat penting mengingat proses ini bertujuan untuk memfokuskan proses fotosintesis tanaman kakao dialokasikan ke bagian buah. Pemangkasan rutin terbukti secara signifikan meningkatkan produksi kakao (Govindaraj \& Jancirani, 2017). Perawatan kakao mendukung Good Agriculture Practices pada budidaya kakao (Asare \& David, 2011). Untuk kegiatan penggantian tanaman yang tidak tumbuh optimal umumnya dilakukan dengan teknik sambung samping (grafting). Perbanyakan tanaman kakao secara vegetatif melalui sistem sambung mampu meningkatkan produktivitas tanaman (Sodré and Gome, 2019).

Sosialisasi juga dilakukan untuk memberi informasi terkait pengeringan biji kakao. Sosialisasi dilakukan dengan bahasa yang sederhana dan mudah dimengerti oleh mitra. Hal ini karena banyak diantara mitra merupakan petani kakao dengan usia di atas 40 tahun. Selepas sosialisasi, data dikumpulkan melalui wawancara untuk mendapatkan respon mitra. Dari 30 peserta yang hadir, keseluruhan menyatakan bahwa kegiatan sosialisasi memberi manfaat dan menjadi pengingat kembali tentang pentingnya perawatan tanaman dan menjaga kualitas melalui pengeringan biji kakao.

\section{Fasilitasi Peralatan Perawatan dan Panen Kakao}

Untuk menjamin kontinuitas kualitas dan kuantitas buah kakao yang merupakan bahan utama penghasil biji kakao, fasilitas perawatan dan panen juga perlu dioptimalkan. Untuk itu, bantuan alat berupa gunting pangkas (pruner), gunting potong, gunting galah (gunting pangkas yang dilengkapi dengan pengait), pisau, dan plastik pelindung buah diberikan pada kegiatan ini. Sedangkan untuk optimalisasi panen, fasilitas peralatan berupa keranjang panen, karung jaring, terpal, ember, timbangan digital, timbangan manual, dan parang juga diberikan (Gambar 2).
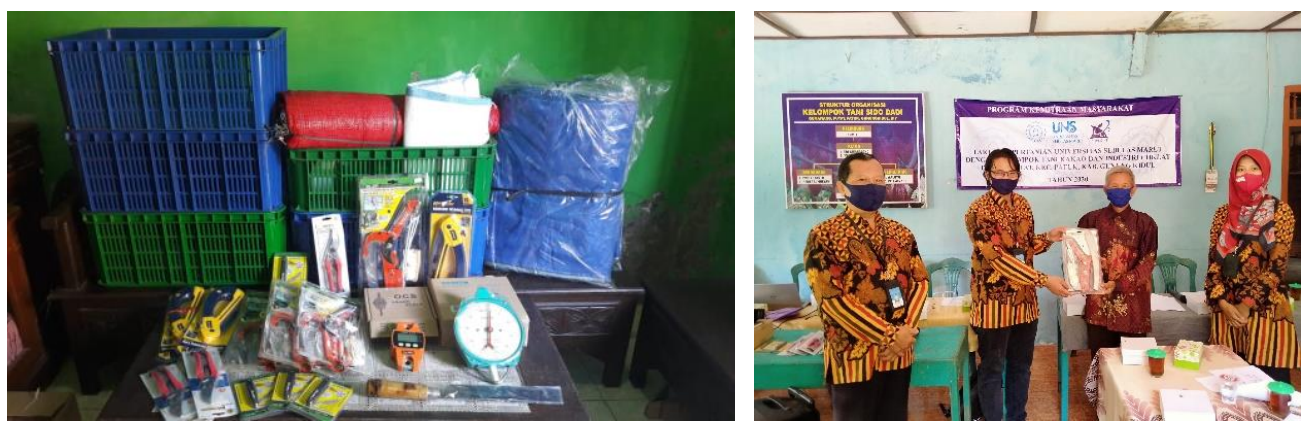

Gambar 2 Fasilitasi alat perawatan dan pemanenan buah kakao
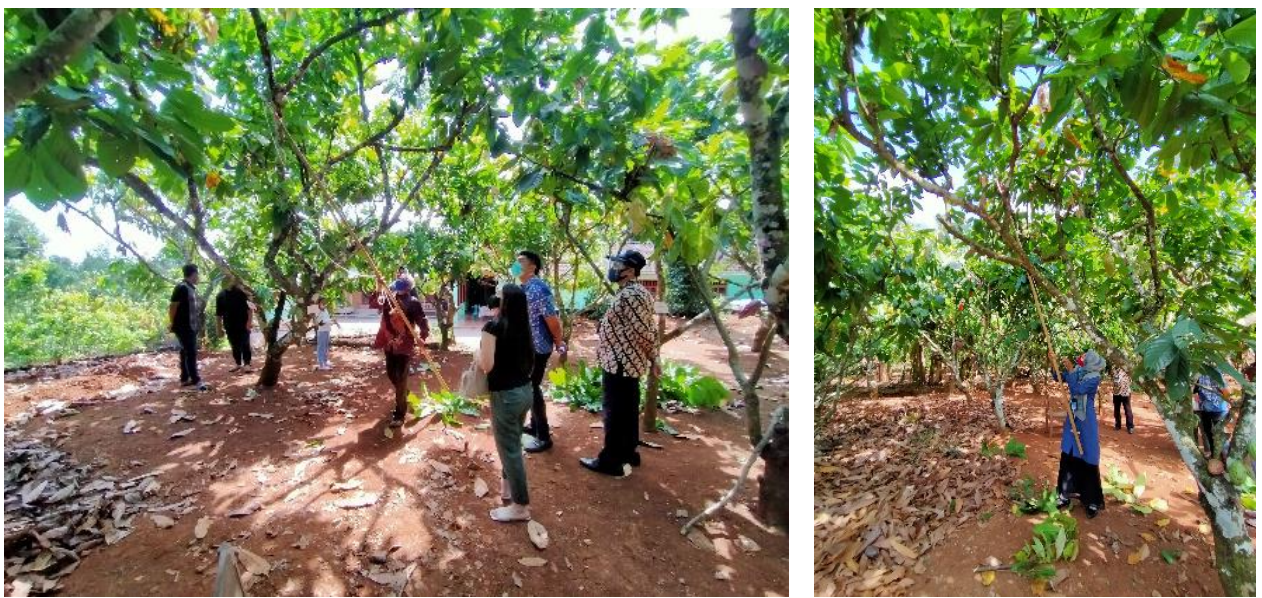

Gambar 3 Pemangkasan pohon kakao 
Peralatan yang diberikan pada mitra juga diuji coba melalui praktek pemangkasan. Praktek pemangkasan dilakukan untuk memberikan sosialisasi praktek kegiatan pemangkasan sekaligus uji coba peralatan yang diintroduksikan. Kegiatan pemangkasan dilakukan oleh tim pengabdian dan mitra (Gambar 3). Pemangkasan diantaranya dilakukan pada tajuk tanaman yang tingginya melebihi 4 meter dan pada tajuk yang saling menutupi. Alat yang digunakan adalah gunting galah. Dalam kegiatan ini, petani mitra menyatakan bahwa gunting galah sangat fungsional untuk menjangkau pucuk-pucuk yang tinggi yang selama ini sulit dipangkas dengan alat yang dimiliki mitra.

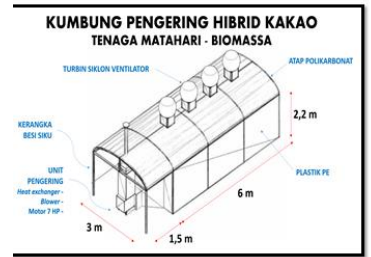

Pembuatan Desain

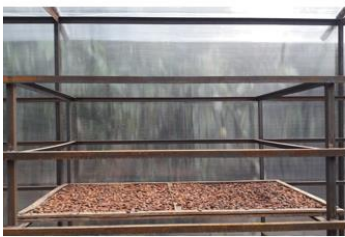

Pamasangan Rak

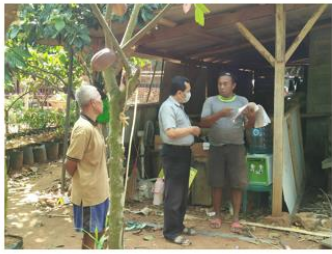

Diskusi Cara Kerja

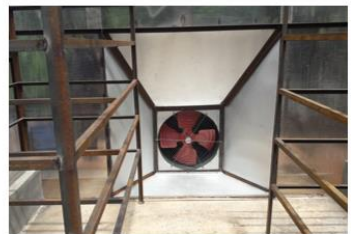

Pamasangan Kipas

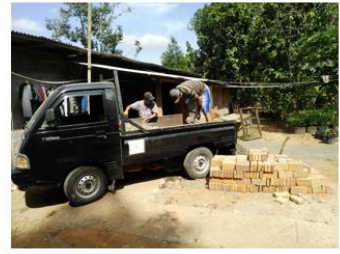

Persiapan Alat dan Bahan

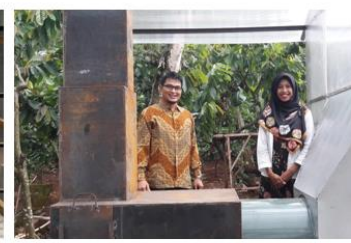

Pemasangan Komponen Pengering

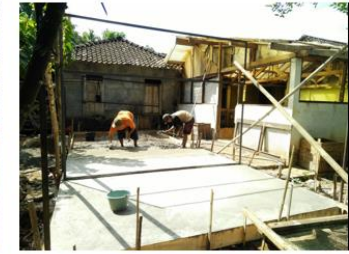

Pembangunan

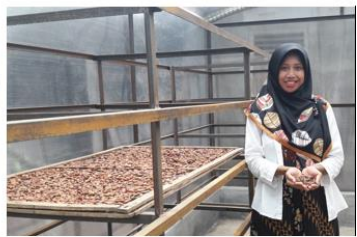

Uji Coba Pengeringan Biji Kakao

Gambar 4 Tahapan pembangunan kumbung pengering. Gambar desain berdasarkan Asari dan Nursani (2016)

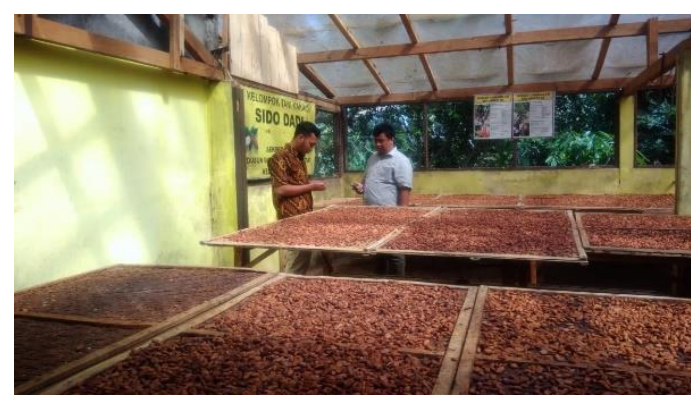

Gambar 5 Kumbung pengering sebelum kegiatan pengabdian

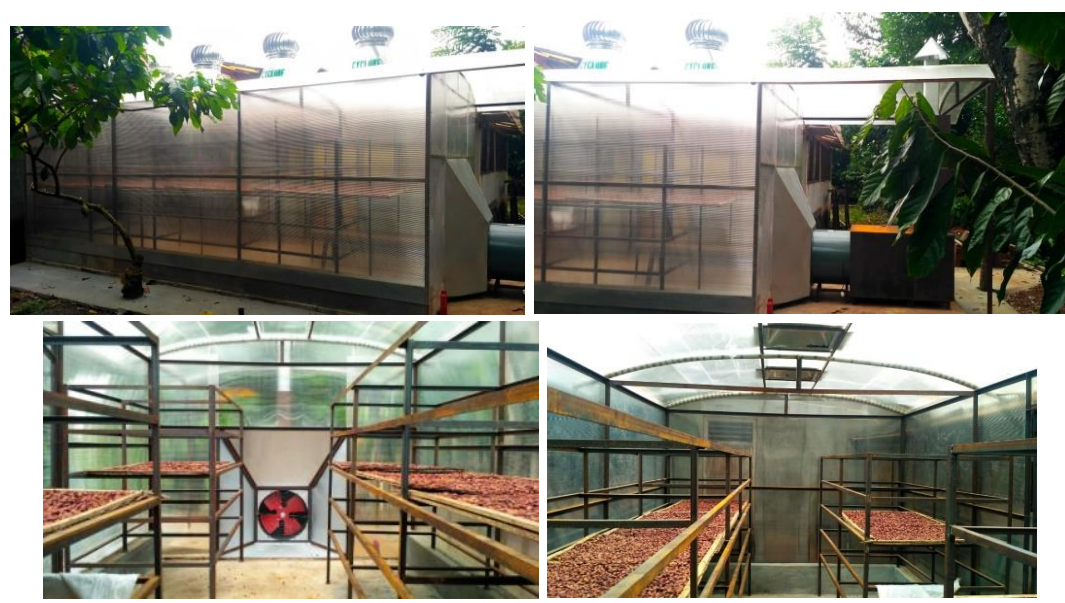

Gambar 6 Kumbung pengering setelah kegiatan pengabdian 


\section{Pembangunan Kumbung Pengering}

Kumbung pengering menjadi salah satu program utama dalam kegiatan ini karena mitra mengalami kendala dalam pengeringan. Selama ini, fasilitas pengering yang dimiliki masih sederhana dan mengalami beberapa kerusakan. Kumbung pengering yang sebelumnya dimiliki hanya mendasarkan pada sinar matahari sebagai energi pengeringannya. Kumbung pengering tersebut berada di belakang rumah dengan atap fiber dan dinding anyaman besi. Beberapa bagian juga sudah mulai rusak sehingga terkadang mengalami kebocoran saat hujan.

Untuk mengotimalkan proses pengeringan biji kakao guna menjamin kontinuitas pemenuhan permintaan pasar, pengabdi mengintroduksikan kumbung pengering sistem hybrid. Sistem pengeringan hybrid merupakan teknologi yang dikembangkan oleh Asari dan Nursani (2016). Adaptasi sistem pengering dapat mendorong peningkatan produksi kakao (Komofale et al. 2014). Dalam pembangunannya, dilakukan diskusi awal untuk memastikan kebutuhan mitra. Dalam kegiatan ini, mitra juga memberikan kontribusi in kind dalam bentuk lahan seluas $30 \mathrm{~m}^{2}$ atau senilai Rp12.000.000, - (asumsi harga tanah = Rp.400.000, - $\mathrm{m}^{-2}$ ).

Kumbung pengering didesain dengan ukuran panjang 6 meter dan 1,5 meter untuk unit pengering, lebar 3 meter dan tinggi 2,2 meter. Kumbung pengering tipe hybrid ini menggunaan energi matahari dan tungku biomassa sebagai sumber energi untuk mengeringkan bahan. Komponen dalam kumbung pengering terdiri atas rumah pengering, rak pengering, tungku pembakaran dan heat exchanger, blower dan turbin. Dinding dan atap kumbung pengering dirakit dengan bahan plastik transparan agar energi matahari dapat ditransmisikan masuk dan memanaskan komponen di dalam kumbung pengering. Kumbung pengering dirancang sesuai dengan ukuran rak pengering biji kakao. Rak disusun menjadi 4 bagian dengan dimensi 5000 x $2000 \mathrm{~mm}$. Selain itu, di dalam kumbung juga dilengkapi ruang untuk mempermudah pergerakan aktivitas di dalamnya. Bahan plastik yang digunakan berupa plastik polikarbonat karena strukturnya yang lebih kuat namun mudah dibentuk (Asari \& Nursani, 2016) (Gambar 4, Gambar 5 dan Gambar 6).

Tabel 1. Hasil evaluasi kegiatan

\begin{tabular}{|c|c|c|c|}
\hline No & Komponen Evaluasi & Sebelum Pengabdian & Sesudah Pengabdian \\
\hline 1 & Pengetahuan terkait perawatan kebun kakao & Mengerti & $\begin{array}{l}\text { Mengerti dan memandang } \\
\text { penting }\end{array}$ \\
\hline 2 & Pengetahuan terkait pengeringan biji kakao & Mengerti & $\begin{array}{l}\text { Mengerti dan memandang } \\
\text { penting }\end{array}$ \\
\hline 3 & $\begin{array}{l}\text { Fasilitas Perawatan Kebun Kakao (gunting pangkas } \\
\text { (pruner), gunting potong, gunting galah (gunting } \\
\text { pangkas yang dilengkapi dengan pengait), pisau, dan } \\
\text { plastik pelindung buah. Sedangkan untuk } \\
\text { optimalisasi panen diberikan fasilitas peralatan } \\
\text { berupa }\end{array}$ & Kurang & $\begin{array}{l}\text { Bertambah secara kuantitas } \\
\text { dan kualitas }\end{array}$ \\
\hline 4 & $\begin{array}{l}\text { Fasilitas Peralatan Panen (keranjang panen, karung } \\
\text { jaring, terpal, ember, timbangan digital, timbangan } \\
\text { manual, dan parang) }\end{array}$ & Kurang & $\begin{array}{l}\text { Bertambah secara kuantitas } \\
\text { dan kualitas }\end{array}$ \\
\hline \multirow[t]{2}{*}{5} & Fasilitas Pengering Biji Kakao & $\begin{array}{l}\text { Ada (kurang optimal) } \\
\text { Metode sederhana }\end{array}$ & Ada, Optimal \\
\hline & & & Sistem Hybrid \\
\hline 6 & Manfaat & - & Bermanfaat \\
\hline 7 & Keberlanjutan & - & Diharapkan terus berlanjut \\
\hline
\end{tabular}

Komponen tungku pembakaran pada kumbung pengering digunakan untuk membakar biomassa berupa kayu, sekam, atau lainnya. Selanjutnya, energi panas yang dihasilkan dalam proses pembakaran akan memanaskan heat exchanger. Adanya heat exchanger memungkinkan udara yang mengalir ke ruangan pengering hanya berupa energi panas tanpa adanya campuran asap dan debu yang dapat menurunkan kualitas hasil biji kakao kering. Blower/Kipas digunakan untuk meratakan atau mensirkulasi udara di dalam kumbung pengering. Prinsip kerjanya dimulai dari heat exchange yang telah menghasilkan udara panas yang bersih. Udara panas yang dihasilkan diratakan oleh blower agar semua ruangan di kumbung pengering memperoleh energi panas tersebut. Blower yang diaplikasikan memiliki tipe aksial dengan diameter 24 inchi. Tipe ini akan menghasilkan aliran turbulen sehingga secara optimal meratakan udara panas. Turbin ventilator pada kumbung pengering ini berperan untuk membantu sirkulasi udara panas dengan cara 
menghisap udara yang membawa uap air sehingga menghasilkan biji yang kering sempurna sesuai kadar air yang diharapkan. Agar dapat bekerja secara optimal, kumbung pengering dilengkapi dengan turbin sejumlah 4 buah dengan diameter 45 inchi yang diletakkan pada atap kumbung (Asari \& Nursani, 2016).

Komponen-komponen dalam kumbung pengering ditujukan untuk memastikan biji kakao mengalami pengurangan kadar air dari 55-60\% menjadi 6-7\%. Kegiatan pengeringan ini berperan signifikan dalam proses biokimia selepas proses fermentasi biji kakao dalam bentuk penurunan rasa pahit, sepat dan asam pada biji kakao (Deus et al. 2018). Dengan berfungsinya kumbung pengering ini secara optimal, hal ini akan berdampak pada durasi penyimpanan produk lebih lama (biji kakao lebih awet), mengurangi biaya produksi, memudahkan distribusi, dan meningkatkan nilai ekonomis produk biji kakao.

\section{Evaluasi Kegiatan}

Hasil evaluasi menunjukkan bahwa masyarakat sangat merasakan manfaat dari kegiatan ini. Hal ini terlihat dari respon terkait sosialisai yang dianggap memberikan dampak positif pada mitra karena mitra menjadi lebih memberikan perhatian atau lebih menganggap penting perawatan dan pengeringan biji kakao. Selain itu, dengan adanya fasilitasi alat perawatan dan panen membuat jumlah peralatan pada Kelompok Tani Sido Dadi menjadi lebih lengkap secara kuantitas dan kualitas. Fasilitas kumbung pengering berkontribusi besar dalam menggantikan ruang pengering yang sebelumnya kurang optimal. Sehingga diakhir kegiatan masyarakat mitra menyatakan kegiatan pengabdian ini bermanfaat dan layak dilanjutkan (Tabel 1).

\section{KESIMPULAN}

Kegiatan pengabdian masyarakat intensifikasi perawatan kakao dan introduksi alat pengering sistem hybrid berdampak positif terhadap mitra. Mitra menyatakan kebermanfaatan kegiatan ini dan keinginan untuk kegiatan berkelanjutan. Introduksi alat perawatan dan kumbung pengering memudahkan petani dalam melaksanakan kegiatan budidaya, panen dan pasca panen biji kakao sehingga dapat meningkatkan kualitas dan kuantitas biji kakao yang dihasilkan.

\section{DAFTAR PUSTAKA}

Asare, R. \& David, S. (2011). Good agricultural practices for sustainable cocoa production: a guide for farmer training. Manual no. 1: Planting, replanting and tree diversification in cocoa systems. Forest \& Landscape Denmark University of Copenhagen

Asari, A., \& Nursani, D. (2016). Rekayasa mesin pengering hybrid tipe rak untuk pengeringan biji kakao. Prosiding Seminar Nasional Inovasi Teknologi Pertanian. Banjarbaru, 20 Juli 2016.

Deus, V. L., de Cerqueira E Silva, M. B., Maciel, L. F., Miranda, L. C. R., Hirooka, E. Y., Soares, S. E., Ferreira, E. S., \& Bispo, E. S. (2018). Influence of drying methods on cocoa (Theobroma cacao L.): antioxidant activity and presence of ochratoxin A. Food Sci. Technol, 38(Suppl. 1), 278-285.

Direktorat Jenderal Perkebunan. 2019. Statistik Perkebunan Indonesia 2018-2020 Kakao. Direktorat Jenderal Perkebunan Kementerian Pertanian. Jakarta, 74 hal

Faradilla, L. (2018). Analisis teknik pemangkasan, pemupukan, panen sering dan sanitasi (P3S) terhadap produktivitas dan pendapatan usaha tani kakao (Theobroma cacao L.) di Kabupaten Pinrang, Bantaeng dan Luwu Timur [Skripsi]. Program Studi Agroteknologi Departemen Budidaya Pertanian Fakultas Pertanian Universitas Hasanuddin Makassar.

Govindaraj \& Jancirani. (2017). Effect of pruning on cocoa (Theobroma cacao 1) on morphological, flowering and yield and quality of cocoa beans. International Journal of Agricultural Science and Research (IJASR), 7(6), 113-118.

Kindangen, H., Hartoyo, S., \& Baga, L. M. (2017). Perkembangan produktivitas, luas lahan, harga domestik, permintaan dan ekspor biji kakao Indonesia periode 1990-2013. Jurnal Manajemen \& Agribisnis, 14(2), 118126.

Komolafe, C. A., Adejumo, A. O. D., Awogbemi, O., \& Adeyeye, A. D. (2014). Development of a cocoa beans batch dryer. American Journal of Engineering Research (AJER). 3(9), 171-176.

Lasisi, D. (2014). A comparative study of effects of drying methods on quality of cocoa beans. International Journal of Engineering Research \& Technology (IJERT), 3(1), 991-996. 
Manalu, M. (2018). Pengolahan biji kakao produksi perkebunan rakyat untuk meningkatkan pendapatan petani. Jurnal Ekonomi \& Kebijakan Publik, 9(2), 99-111.

Noor, M. (2011). Pemberdayaan masyarakat. Jurnal Ilmiah CIVIS, 1(2), 87-99.

Sodré, G. A., \& Gomes, A. R. S. (2019). Cocoa propagation, technologies for production of seedlings. Rev. Bras. Frutic., 41(2), 1-22. 